\title{
Component or Accessory Incompatibility
}

National Cancer Institute

\section{Source}

National Cancer Institute. Component or Accessory Incompatibility. NCI Thesaurus. Code C63020.

Problem associated with the incompatibility of any device while being operated in the same use environment thereby leading to a dysfunction between the devices. 